\title{
TRANSFORMACIONES EN EL SISTEMA DE CREDITO Y CRISIS \\ DE LAS ECONOMIAS MONASTICAS \\ EN ARAGON A FINES \\ DEL ANTIGUO REGIMEN
}

ANGELA ATIENZA LOPEZ

Hoy día es suficientemente conocido el papel dominante que durante la Edad Moderna mantuvo la Iglesia en el desarrollo del sistema crediticio de la sociedad tardofeudal ${ }^{1}$.

El censo consignativo pasa por ser la principal figura crediticia de la épo$\mathrm{Ca}^{2}$. Nobleza, concejos, campesinos... acudían a él para hacer frente a sus necesidades y constituían los principales demandantes de capital, mientras que las instituciones eclesiásticas, especialmente monasterios y conventos, llegaron a convertirse en los principales prestamistas y, por tanto, principales beneficiarios de esta forma de detracción de excedente. En el siglo XVIII la proporción del capital censal y sus réditos que aparecía dominada por la Iglesia era considerable: las estimaciones realizadas por M. Artola indican que en Castilla el 73 por 100 de las rentas censales estaban en manos del clero $^{3}$, mientras que en Aragón la evaluación realizada por G. Pérez Sarrión, para el caso zaragozano, asciende al 82,3 por $100^{4}$. De forma más concreta, otros estudios confirman también este protagonismo ${ }^{5}$. Sin embargo, es necesario advertir que de las rentas que debían percibir los eclesiásticos por este concepto a las que realmente cobraban había una distancia considerable...

El propósito de estas páginas es contribuir, desde Aragón, al estudio del inicio de las transformaciones que se operaron en el sistema crediticio a finales del Antiguo Régimen desde una doble perspectiva: la crisis del régi-

\footnotetext{
1 Sobre la cucstión del crédito en esta época, Ruiz Martín (1970).

2 Sobre el origen del censo y su vinculación con el momento en el que se estableció la persecución de la usura, Clavero (1977 y 1985).

3 Artola (1977), p. 48. A partir del Catastro de Ensenada.

4 Pérez Sarrión (1984), pp. 201-202.

5 A mediados del siglo XVIIr, los eclesiásticos controlaban en Medina de Rioseco el 95 por 100 del capital censal de la ciudad. Véase Yun Casalilla (1987), p. 344. En la zona sur del País Valenciano, según el Padrón de 1717 de la ciudad de Orihuela, la mitad de los capitales invertidos en censales procedía del clero regular. Véase Millán (1984), p. 281. El mismo predominio de las instituciones eclesiásticas destacan Lemeunier y Pérez Picazo (1984), p. 102; Marcos Martín (1985), p. 92, y Gómez Alvarez (1977), pp. 5-25.
} 
men censal y el desarrollo de una nueva figura crediticia, todo ello a partir del conocimiento de la propia situación económica de las comunidades religiosas, y esto porque el proceso de cambio no iba a afectar únicamente a la clase campesina ${ }^{6}$, sino también a las mismas instituciones eclesiásticas, que se vieron atrapadas entre la crisis del mecanismo de crédito que ellas habían dominado secularmente y el surgimiento de nuevas figuras, con otro alcance y otros intereses, claramente contradictorios con el estado de dominio de la propiedad feudal.

Uno de los factores que jalonaron la llamada "crisis de las economías monásticas" durante el primer tercio del Ochocientos fue, sin duda, el problema de los censos. Es cierto que esta partida de los ingresos conventuales había venido generando dificultades desde muchos años atrás. Ya a mediados del siglo XVII, la Cartuja de Aula Dei, situada en las proximidades de Zaragoza, exponía lo siguiente:

"... entonces [refiriéndose a los primeros años del Seiscientos] se tenia por buena bazienda los censales. Pero en tiempos presentes del año 1643 es de los censales la bazienda más perdida y según va de aumento el daño dellos, no se puede aguardar sino la total perdición dellos' ${ }^{7}$.

Pero, a pesar de la contundencia de estas palabras, los eclesiásticos siguieron invirtiendo en $\operatorname{censos}^{8}$, si bien durante el siglo XVIII se advierte ya una cierta reorientación de la política prestamista por parte de los conventos, que van a restringir la cesión de capitales a los concejos y a la alta nobleza y se van a centrar en el cargamiento de censos a particulares, como hemos podido constatar en el caso de los religiosos zaragozanos?.

Sin embargo, los conventos seguían manteniendo un volumen muy alto de capital censal y, desde finales del Setecientos, la situación por la que atravesaban los réditos correspondientes se agravó. Los libros de contabilidad de las comunidades religiosas muestran cómo el cobro de estas rentas era extraordinariamente irregular, hasta el punto de poder decir que, con los censos, todo resultaba posible pero nada era previsible: de no cobrar durante años las rentas de cualquier censal a percibir, en el mismo año, tres, cuatro o más pensiones atrasadas... Y en esta evolución dispar influían, sobre todo, las acciones de los concejos y de la alta nobleza en la medida en que, tanto por el número de censos contraídos como por el volumen del

\footnotetext{
- Fernández de Pinedo (1985).

AHN, Sección Clero, Leg. 8436.

\& Las razones por las que los censos siguieron siendo útiles para las instituciones eclesiásticas han sido explicadas por Yun Casalilla (1987), p. 362.

9 Atienza (1987), pp. 67-103.
} 
capital en jucgo, constituían, por el orden citado, los principales censatarios de los conventos y eran, precisamente, los menos corrientes en sus pagos. El siguiente cuadro, en el que se recoge la evolución de los ingresos procedentes de censos del Monasterio de Santa Engracia de Zaragoza durante el período 1816-1834, puede ser bastante expresivo ${ }^{10}$.

Rentas de censos del Monasterio de Santa Engracia (1816-1834)*

\begin{tabular}{|c|c|c|c|}
\hline & $\begin{array}{c}\text { Censos } \\
\text { concejiles }\end{array}$ & $\begin{array}{c}\text { Censos } \\
\text { de nobles }\end{array}$ & $\begin{array}{c}\text { Cerisos } \\
\text { de particulares }\end{array}$ \\
\hline 1816-1819 ……………....... & 1.079 & 1.229 & 1.866 \\
\hline $1824-1827 \ldots \ldots$ & 569 & 1.403 & 3.686 \\
\hline 1828-1831 ….......................... & 0 & 957 & 2.168 \\
\hline $1832-1834$ & 72 & 772 & 2.086 \\
\hline
\end{tabular}

* Medias anuales en cada período. En reales de vellón.

Fuente: Elaboración propia. AHN, Sección Clero, Libro 18786.

Las dificultades de los municipios para hacer efectivas sus obligaciones censales no eran nuevas, pero en estos años la morosidad alcanzó proporciones inéditas. No era ninguna justificación, entonces, que la Cartuja de la Concepción declarara en un manifiesto realizado en 1817: "De los censos concejiles apenas se ha cobrado nada desde el año [180] ${ }^{11}$. No era extraño tampoco que la Cartuja de Aula Dei, que en 1809 debía percibir por rentas censales un total de 44.205 rs. vn. al año, el 78 por 100 de los cuales provenían de censos impuestos sobre los concejos aragoneses, apenas llegara a ingresar, durante el período 1830-1834, 1.400 rs. vn. de media anual por este concepto ${ }^{12}$. Ni las concordias firmadas continuamente, que estipulaban intereses inferiores al 3 por 100 que fijaba la ley, hacían posible que los religiosos pudieran cobrar sus rentas. Los censos impuestos sobre la nobleza, por su parte, no presentaban una situación mejor.

De la misma forma, los ingresos que debían proceder de todas las obligaciones que la monarquía había contraído con los regulares por distintas

10 Su lectura, no obstante, exige tener en cuenta que el volumen de la renta teórica procedente de concejos y nobles era bastante superior a la de los censos de particulares. Desconocemos la proporción exacta en el caso del Monasterio de Santa Engracia, pero nada hace pensar que su situación fuera diferente a la del resto de las comunidades zaragozanas.

11 AHN, Sección Clero, Leg. 8583, "Certificación del total Producto correspondiente al siguiente quinquenio en esta Cartuja de la Purisima Concepción. Año 1817". El quinquenio al que se refiere es 1805,1806 y 1807 , y 1815 y 1816.

12 En concreto, 1.392 rs. vn. Elaboración propia a partir de los datos de AHN, Sección Clero, Libro 18757. Los datos de 1809, en Atienza (1987), p. 97. 
vías tampoco pasaron por su mejor época. Vales reales, préstamos voluntarios que redituarían un 3 por 100 anual, propiedades que se vendieron durante la llamada "Desamortización de Godoy" y cuyo capital tambićn debía producir una renta anual del 3 por 100, censos cuyo pago había asumido la hacienda real, como los de las Generalidades del Reino de Aragón o los impuestos sobre la Renta del Tabaco..., todo quedó pronto en el olvido. "Nada se ba cobrado desde la supresión del Convento por los franceses" es la frase que anotaba la comunidad de San Ildefonso de Zaragoza para referirse a las 903 libras de pensión anuales que debía recibir por los censos que tenía impuestos sobre las Generalidades del Reino de Aragón ${ }^{13}$, y, como ella, el resto de los institutos que habían impuesto capitales sobre las Generalidades o la Renta del Tabaco: comunidades zaragozanas como las de San Agustín, Santa Mónica, el Carmen, San Pedro Nolasco, Santa Engracia, agustinos descalzos, San Vicente Ferrer, etc., tal y como se señalaba en el Catastro de la ciudad ${ }^{14}$. Algunas de estas comunidades, además, habían invertido en vales reales y tampoco les fué mejor. La Cartuja de Aula Dei, que poseía 26 vales con un valor capital total de 4.800 pesos, también señalaba en 1817: "De los sobredichos 26 vales nada se ba cobrado desde el año $18077^{15}$, y, de la misma forma, de los préstamos voluntarios que el rey había solicitado a los religiosos en 1798 , nunca más se supo ${ }^{16}$.

Se comprende, en definitiva, que las corporaciones eclesiásticas aceptaran gustosas y no pusieran ningún reparo ante las cancelaciones y luiciones de censos con pérdidas considerables sobre el capital correspondiente y las pensiones atrasadas, como las que efectuó la ciudad de Zaragoza durante el primer tercio del siglo $\mathrm{XIX}^{17}$ :

"Esta tarde [escribía un fraile dominico de Zaragoza en su diario] ba babido en la Aula del Convento Junta de Censalistas a que

13 AHN, Sección Clero, Libro 19727.

14 A(rchivo) M(unicipal) Z(aragoza), Catastro, Cajas 23, 24 y 25. Pliegos correspondientes a las comunidades que se señalan.

15 AHN, Sección Clero, Leg. 8440. Manificsto de las rentas de la comunidad.

16 La misma Cartuja de Aula Dei lo señalaba en 1817: "Hai un empréstito que bizo este Monasterio a S.M. en 27 de Agosto de 1798 de ciento veinte mil reales de vellón con la pensión de un tres por ciento y se ha cobrado hasta el año 1807, y desde dicho año nada de ba cobradon (ibid.). Pero, como es sabido, la forma en que la crisis financiera del Estado afectó a los eclesiásticos no quedaría únicamente ceñida a esta pérdida de rentas e incumplimiento de las obligaciones contraídas por parte de la hacienda real, sino que, además, se iba a incrementar la presión fiscal sobre sus rentas. Sobre las dificultades de la hacienda y la actitud de los privilegiados en general, véase García Sanz (1977), pp. 412-434 y 451-453. También, Fontana (1974), pp. $181-216$.

$17 \mathrm{La}$ aceptación de luiciones desfavorables, no obstante, es un fenómeno que ya se había iniciado a finales del siglo anterior y constituye uno de los síntomas más claros de la crisis que padecía el régimen censal, de su devaluación efectiva. Véase Atienza (1987). 
ban concurrido mucbos a mandar. Ha sido para luir pensiones vencidas de atrasos de muchos años, y el Convento por su Prior ba mandado perdiendo el 85 por ciento de modo que las pensiones atrasadas ascendían a más de 9 mil escudos, perdonando el 85 por ciento dicen que cobrará el Convento mil quatrocientos treinta y tantos escudos de una deuda de que ya no se bacía caso ni casi babía memoria, esto es de los censales de la Ciudadin.

Pero si hasta entonces estas cancelaciones se habían llevado a cabo con los concejos y la alta nobleza, el espectro de los favorecidos por ellas empezaba a ampliarse como reflejo, sin duda, del incremento de las dificultades de muchos censatarios particulares, que se resentían ante el pago de las pensiones correspondientes. La misma Cartuja de la Concepción, que, como hemos visto, manifestaba no percibir apenas nada de los censos concejiles desde 1805, declaraba también: "De los demás hay mucbos atrasos" ${ }^{19}$. En otras ocasiones, por otra parte, se ponía de manifiesto una actitud de clara resistencia que los conventos, en las actuales circunstancias financieras, no podían solucionar por la vía ejecutiva, como claramente exponía la comunidad de religiosas de Santa Inés de Zaragoza cuando anotaba en su libro de recibos el ingreso de 159 libras 7 sueldos 8 dineros, que había pagado Ramón Simón, vecino de la localidad de Tauste, por la luición de su censo, y explicaba: "Se le ban perdonado 40 l. $12 \mathrm{ss.} 8 \mathrm{~d}$. de capital y todas las pensiones que debia desde el año 1806 basta el de 1827. Se bizo esta composición por no llevar a pleito pues se negó a pagan 20.

Esta era, en resumen, la suerte que corrian los censos y sus titulares a finales del Antiguo Régimen. Al margen de las resistencias a pagar por parte de los particulares ${ }^{21}$, el problema de fondo era, en definitiva, la propia imposibilidad de ejecutar las hipotecas sobre las que descansaban los capitales censales de mayor entidad, los de concejos y nobles. La situación jurídica

18 B(iblioteca) U(niversitaria) Z(aragoza), Manuscrito 34, fol. 196 (23 de agosto de 1819). En 1825 se hicieron más luiciones [véase A(rchivo) H(istórico) $\mathrm{P}$ (rovincial) Z(aragoza), Registros de Hipotecas, Zaragoza, 1825]; el convento de Santa Inés, por ejemplo, afirmaba haber recibido ese año "465 libras 10 sueldos importe de tres censos sobre la ciudad de Zaragoza cuyo capital era 2.750 libras y se perdio al 83 por 100 como consta de la escritura de luición becha por don Gregorio Ligerio, notarion. AHN, Sección Clero, Libro 18838, recibo del año 1825. En el mismo libro aparecen otras cancelaciones desventajosas, cuya aceptación, por otra parte, fue bastante común entre las comunidades aragonesas porque, en definitiva, era preferible, sobre todo en una situación de apuros económicos, perder sobre el capital de un censo una cantidad importante que continuar sin percibir los réditos correspondientes.

19 AHN, Sección Clero. Leg. 8583.

20 AHN, Sección Clero, Libro 18838 , recibo del año 1829.

21 Que, en última instancia, estarían también ligadas y serían reflejo de la pérdida de poder coactivo por parte de los religiosos: su economia, como hemos visto, no estaba para iniciar pleitos. 
de las propiedades de ambos lo impedía. Esto constituía, desde nuestro punto de vista, la razón de fondo de la crisis del sistema censal. A una situación escandalosa de incumplimiento generalizado de las condiciones de los contratos censales se unían las dificultades, que el mismo sistema imponía, para dar una solución ejecutiva.

Pero, paralelamente a este proceso de crisis del sistema crediticio tardofeudal y a la decadencia de la capacidad financiera de la Iglesia, empezaba a desarrollarse un nuevo régimen de préstamos, ya no vinculado a las necesidades de la propiedad feudal y la clase dominante, sino ligado a los intereses de la clase ascendente. Veámoslo.

En primer lugar, el hecho de que las instituciones eclesiásticas ejercieran durante la Edad Moderna el papel de principales censalistas no debe hacernos olvidar que, en ocasiones, también actuaron como censatarios o solicitantes de capital a censo, si bien es cierto que el origen de sus necesidades era de carácter coyuntural y puntual, incluso artificial. Interesa destacarlo no sólo porque refleja la incidencia mayor o menor del censo en una determinada economía en función del carácter -estructural o coyuntural- de la problemática que lleva a la solicitud de un préstamo censal ${ }^{22}$, sino también porque contribuye a la mejor comprensión del impacto que significó para las economías monásticas el estrechamiento del mercado de capitales a censo.

Durante el siglo XVIII, los problemas económicos de las comunidades religiosas mostraban un carácter más subjetivo que objetivo en la medida en que la solicitud de dinero a censo estaba vinculada no a necesidades vitales, de supervivencia, sino a necesidades de expansión. ¿Cómo explicar de otra forma que una comunidad como la del Carmen Calzado de Huesca, por ejemplo, presente una situación que aparentemente resulta similar a la vivida por la generalidad de los conventos a partir de $1814^{23}$ y que, al mismo tiempo, esté adquiriendo bienes inmuebles, inmersa en pleno proceso de expansión de su patrimonio? ${ }^{24}$.

22 Hecho que ya fue puesto de manifiesto por Viñas y Mey (1941), p. 35, y también han destacado Ruiz Martín (1975) y Bennassar (1983), pp. 244-245.

${ }_{23}$ En el libro de acuerdos de la comunidad se nos presentaba la siguiente situación: "Sea memoria que en 28 de mayo de 1772 el P. Fr. Nicolás Peña... propuso a la Comunidad que se ballaba estar gravada con 600 escudos de deudas particulares contraidas legitimamente para subvenir las necesidades indispensables que babia padecido y que en el dia los Acreedores nos pedian les devolviessemos su dinero... y pensara la Comunidad el medio para satisfacerles o bien fuera vendiendo o bien tomando dinero a censos... [se tesolvió] que la Comunidad tomara a censo." AHN, Sección Clero, Libro 4638, fol. $3 \mathrm{v}$.

24 Ocho meses antes, el mismo convento estaba comprando dos viñas y dos campos. En cl mismo año de 1772 compraba otra viña con parte del dinero que había tomado a censo. Al año siguiente adquiría otro campo... Ibid., fols. $3 v$ y 4 . Sobre el proceso de expansión de la propiedad territorial de los conventos zaragozanos durante el Setecientos, Atienza (1988), pp. $141-158$. 
Los "problemas" y las necesidades, efectivamente, presentaban un contenido que casi rozaba en la ironía. Pero, a partir de 1814, las dificultades, además de generalizarse a la mayoría de las corporaciones, ya no reflejarían ese carácter ficticio, sino que eran reales y mostraban un alcance de mayor envergadura ${ }^{25}$. En estos momentos, los conventos siguieron recurriendo al préstamo de dinero a censo, pero la situación se había trastocado y el capital censal ahora no se "invertía", no venía a apoyar o a facilitar un proceso de expansión patrimonial, sino que era consumido rápidamente, con todas las consecuencias que esto tenía. Sin embargo, este cambio de orientación, aun con ser importante, no fue lo más decisivo. Mucha mayor trascendencia para las economías necesitadas de préstamos iban a tener las transformaciones que estaban empezando a gestarse en el seno del propio sistema crediticio ${ }^{26}$.

Para empezar, todo parece indicar que el mercado del préstamo de capitales a censo se estaba cerrando en Aragón; al menos esto es lo que se deduce del hecho de que las comunidades religiosas, a partir de 1814, se vieran precisadas a endeudarse a través de otro tipo de crédito que poco tenía que ver con el censo consignativo. La obligación, cuyas condiciones resultaban mucho más duras que las del "cómodo" censo, se estaba imponiendo como la nueva figura del régimen crediticio, que haría sufrir sus primeras consecuencias también a los religiosos. Así se expresaba en 1814 el Monasterio de Santa Engracia de Zaragoza:

"dixo su Reverencia que en la urgente necesidad de buscar dinero assí para la manutención de los monges como para pagar al Maestro carpintero y a otros oficiales que babian trabajado en la obra y a quienes se debian sus trabajos se babia informado que el único medio de socorrerse sin vender fincas era buscar dinero a préstamo con algún lucro... y que babiendo becho algunas diligéncias babia ballado un sugeto, que entregaria Mil Duros con la condición de que se le entreguen dentro de tres años Mil y doscientos quarenta Duros... y se ha de señalar alguna finca para la seguridad, y el Capitulo, atendida la necesidad en que la Comunidad se halla convino en todo ello: por lo que acto continuo recibió los Mil Durosn" 27.

25 Sobre la crisis de las economías monásticas pueden consultarse varios trabajos, que cubren distintas zonas de la Península: Fontana (1974), Llopis Agelán (1980), Villares (1982), González de Molina (1985), principalmente pp. 221-258, y López García (1987 y 1990).

26 Sobre esta cuestión, pero centrándose en el ámbito del crédito rural y su incidencia, véase Fernández de Pinedo (1985).

27 AHN, Sección Clero, Libro 19862, fol. 9. Se hipotecó un olivar en la huerta de Zaragoza de 8 cahíces de tierra. 
Las condiciones, por tanto, las imponía el prestamista y, lógicamente, eran variables. Así, en 1819, el convento del Carmen de Zaragoza recibía por vía de préstamo 1.072 libras 10 sueldos "para atender a la reparación de nuestro convento y urgencias de la Comunidad,, con las siguientes condiciones:

"Primeramente que el préstamo ha de ser a estilo y ley de comercio con el Rédito o interés anual de un seis por ciento. $Y$ debe durar por espacio y tiempo de seis años (...). Que si en qualesquiera de los expresados seis años pareciese a dicba nuestra Comunidad entregar y devolver a dicha Javiera Medrano o a sus babientes derecbo la enunciada cantidad de mil y setenta y dos libras y diez sueldos por tercias partes, podremos verificarlo (...). Y en igual forma dicha Javiera Medrano o sus babientes derecbo podrán en qualesquiera de los nombrados seis años, pedir y exigir de nuestra Comunidad la enunciada cantidad... por tercias partes..." ${ }^{28}$.

Como puede apreciarse, el contenido de este tipo de préstamos nada tenía que ver con el del censo consignativo. En primer lugar, fijaba plazos para la devolución del capital prestado, en contraposición al censo, que, en el caso de no ser perpetuo, vencía a voluntad del deudor. En segundo lugar, sobrepasaba de forma importante el interés legal del censo, que había quedado establecido, a partir de 1750 en la Corona de Aragón, en el 3 por $100^{29}$. Y, en tercer lugar, la obligación, en la mayoría de los casos, no admitía una indefinición de la hipoteca como, en tantas ocasiones, había sucedido con los censos ${ }^{30}$.

Desde nuestro punto de vista, el hecho de que los regulares aceptaran, como parte deudora, la firma de un contrato de obligación, con las características señaladas, demuestra que ya no era fácil encontrar dinero a censo entre los que disponían del líquido suficiente para efectuar préstamos ${ }^{31}$.

28 A(rchivo) Pr(otocolos) Z(aragoza), Anastasio Marin, 1819 , fols. $174 \mathrm{v}-175 \mathrm{v}$.

29 En los casos que hemos expuesto, los intereses de las obligaciones superaban, incluso con amplitud, los tipos que se utilizaron normalmente en el País Vasco: "Fue precisamente en las décadas 1800-1809 y 1810-1819, cuando los tipos de interés scituaron en su nivel más alto, 4,36 y 4,46 por 100, respectivamente." Fernández de Pinedo (1985), p. 302.

30 Sobre todo con los censos concejiles y de nobles: Atienza (1987).

31 No fueron únicamente el Monasterio de Santa Engracia o el convento del Carmen, de Zaragoza, las corporaciones que tuvieron que plegarse a este tipo de contratos, también otras comunidades zaragozanas como la de carmelitas descalzas de San José, el colegio de San Pedro Nolasco, el convento de San Lázaro, el de Santa Catalina, el colegio del Carmen, el convento de San Lamberto, el de Santa Mónica y los agustinos descalzos del lugar de Alagón..., debieron aceptar los plazos de devolución y los intereses que les imponían las escrituras de obligación que habían firmado. AHPZ, Registros de Hipotecas, Zaragoza, años 1815, 1820, 1825, 1832 y 1835. Para los agustinos de Alagón: AHN, Sección Clero, Libro 18550 , consultas de 5 de enero y de 30 de septiembre de 1819. Por otra parte, también es 
No era fácil, desde luego, pero tampoco resultaba todavía imposible: muchas comunidades lograron encontrar quien les hiciera préstamos a censo..., pero lo que sí se demostró como prácticamente imposible fue el que éstos se hicieran por un interés igual o inferior al 3 por 100 que marcaba la ley. Así, en el proceso de transición, las primeras obligaciones influían en los últimos censos, al margen de que, por supuesto, la ley de la oferta y la demanda jugara también a favor de los potenciales censalistas en cuanto al tipo de interés que se podían permitir imponer.

Efectivamente, el clero regular conseguía encontrar préstamos bajo la forma censal, pero a un interés del 4 por $100 \mathrm{y}$, más frecuentemente, del 5 e incluso del 6 por 100. El convento del Carmen, de Huesca, por ejemplo, cargaba, en 1828, "la cantidad de 100 duros con el rédito vitalicio anual del 5 por cien" y, un año más tarde, "400 duros con el rédito vitalicio anual del 6 por cien $^{32}$. Muchas otras comunidades ya habían pasado por la misma situación ${ }^{33}$. Sin embargo, también es necesario señalar que, en algunas ocasiones, resulta difícil determinar a partir de la documentación privada qué modalidad de préstamo estaban aceptando las comunidades religiosas. En 1820, por ejemplo, se escribía en el libro de actas del Monasterio de Santa Engracia lo siguiente:

"... y el préstamo que un sugeto babia adelantado a la Comunidad de 17.000 rs. un. y para cubrir dicho préstamo se habian hecho varias diligencias de buscar dinero a censo. $Y$ abiendo encontrado quien lo adelantase Su paternidad dixo lo habia encontrado al cinco por ciento baciendo la Comunidad una obligación de devolverlo dentro de tanto tiempo (sic) $)^{34}$.

Como se ve, en algunos casos se llamaba censo a lo que en realidad era una obligación, seguramente debido a la confusión e indeterminación propia del momento de transformación del censo y de transición entre ambas

necesario tener en cuenta que, durante los siglos anteriores, las necesidades de numerario de las comunidades religiosas normalmente habían sido cubiertas por los préstamos censales que les otorgaban otros eclesiásticos (seculares o regulares), pero durante el primer tercio del siglo xix - dado el carácter general del fenómeno de crisis de las economías conventuales y el agotamiento de su capacidad financiera - los religiosos se vieron obligados a recurrir al exterior para solicitar un crédito.

32 AHN, Sección Clero, Libro 4638 , fols. $32 \mathrm{v}$ y 34.

33 Los conventos zaragozanos de San Agustín (AHPZ, Registros de Hispotecas, Zaragoza, 1820); de Santa Mónica, que tuvo mejor suerte y logró encontrar dos censos al 3 por 100 y otro al 4 por 100 (AHN, Sección Clero, Libro 18813); la comunidad de Santa Inés (AHN, Sección Clero, Libro 18838); la de Santo Domingo (BUZ, Ms. 34), o el convento de la Merced, de Huesca (AHPHU, Sección Hacienda, Leg. T. 9.", 12), por citar algunos casos.

${ }^{34}$ AHN, Secrión Clero, Libro 19862, fol. 31v. 
modalidades crediticias. En cualquier caso, lo que interesa destacar es que mientras los réditos de censos que percibían las instituciones se habían quedado estancados en un interés del 3 por $100^{35}-\mathrm{y}$ esto si lograban hacer efectivas las pensiones en su totalidad-, ellos estaban pagando censos a un interés superior, cuando no se encontraron obligadas a las condiciones de una nueva figura crediticia.

Las corporaciones religiosas, que, como destacados censalistas, habían constituido hasta entonces verdaderas instituciones financieras dentro del sistema feudal, se veían ahora, por sus circunstancias, subordinadas a los agentes del capital, a los nuevos prestamistas y a sus nuevas condiciones, obligadas a devolver el dinero prestado en el plazo que les imponía la parte acreedora.

Ya hemos visto en el texto procedente de las actas capitulares del Monasterio de Santa Engracia, citado más arriba, cómo la comunidad - una de las más potentes de Zaragoza - se vio obligada a obtener un nuevo préstamo, a reproducir el círculo de endeudamiento, para satisfacer y cumplir las condiciones de una obligación contraída con anterioridad. No fue éste el único caso, ni tampoco fue ésta, al menos en principio, la resolución más grave.

Mucho más significativas y de mayor trascendencia fueron otras resoluciones, como vamos a ver. En 1820, la comunidad de San Pedro Nolasco de Zaragoza enviaba el siguiente memorial al Provincial de su Orden:

"El Rector y Religiosos del Colegio de San Pedro Nolasco de la Ciudad de Zaragoza exponen a $V$. Rdo. que los atrasos y urgencias de esta casa le precisaron a tomar en dos ocasiones y en calidad de préstamo 7.500 rs. vn. de Don Valero Ubedo, y 17.360 rs. vn. de Don Antonio Figueras, vecinos de la misma, y ballándose en la necesidad de devolver dichas cantidades no encuentran otro arbitrio que el de enagenar un campo que posee en el término de Valimaña, que (...) tiene útiles 8 cabices 1 arroba..."

Días después, el Colegio se obligaba a pagar a don Antonio Figueras la cantidad que les había prestado y para ello le traspasaron la propiedad del campo de que habla el texto (algo más de 3 Has. de regadío), tasado en 30.000 rs. vn., de los que el capital prestado "quedó en abono y parte de pagon ${ }^{36}$. A este sistema de traspaso de una propiedad al prestamista como

35 Este era, como sabemos, el interés fijado legalmente, aunque, en la práctica y por lo que se refiere a los censos de concejos y nobleza, el tipo de interés real, tras sucesivas concordias, había quedado establecido uno o dos puntos por debajo de la tasa legal. Atienza (1987), pp. 79-86.

36 A.Pr.Z., Anastasio Marin, 1820, fols. 192-194v. 
pago de una deuda se le denomina «insolutundación». La misma operación se vieron obligados a ejecutar otros conventos zaragozanos, como el de San Lázaro $^{37}$ o el de San Lamberto ${ }^{38}$.

En estos casos, las obligaciones acabaron suponiendo para los conventos la pérdida directa de la propiedad en favor del prestamista, pero no fueron éstas las únicas ocasiones en que las deudas contraídas terminaron afectando a la integridad de los patrimonios conventuales. El peso de las deudas o la presión de los acreedores quedaron muchas veces reveladas entre las razones que llevaron a los conventos a solicitar las licencias correspondientes que les permitirían enajenar alguna/s fincas. Sin necesidad de que mediara la insolutundación, las deudas y las obligaciores acabaron en la venta de propiedades. Muy explícitamente lo exponía el Provincial de la orden de la Merced en la licencia que en 1816 concedía al convento de San Lázaro de Zaragoza:

"Por quanto por parte [de dicha comunidad] ... se nos ba pedido $y$ bumildemente suplicado que, por razón de las deudas contrabidas por dicho nuestro Convento para la reedificación, alimentos y arreglo de la Casa, en censos que se han cargado y oficiales que en ella han trabajado, se halla dicho nuestro Convento en la imposibilidad de satisfacer a sus Acreedores sin que eche mano de las fincas que posee: por tanto fuésemos servidos concederles nuestra bendición y licencia para vender basta la cantidad de siete mil duros que juzgan necesario para desempeñarsè ${ }^{39}$.

Efectivamente, las deudas y las obligaciones contraídas en estos momentos por las comunidades religiosas, como recurso alternativo a la venta de las propiedades, acabaron convirtiéndose en un arma de doble filo, algo que nunca les había ocurrido a través del censo consignativo. Es cierto, como dijimos, que la situación financiera en la que se encontraban los conventos no era la misma que en el siglo anterior, está claro, pero tampoco el carácter del tipo de préstamos era el mismo y, en última instan-

37 Esta comunidad de mercedarios también había recibido un préstamo del mismo don Antonio Figueras, de 74.400 rs. vn., y, para su devolución, el convento tuvo que insolutundarle y traspasarle dos casas de su propiedad en la ciudad de Zaragoza. APrZ, Anastasio Marin, fols. 133 y ss.

38 La insolutundación del convento de San Lamberto se realizó en 1820 a raíz de un préstamo de 200 libras que había recibido dos años antes de Martín de Gracia, labrador y vecino de Zaragoza, y que no pudo devolver, por lo cual los religiosos le cedieron la propiedad de un campo de dos cahíces de tierra en el término de la huerta zaragozana de Almozara, evaluado en 280 libras: "Y en su virtud el dicho Martín nos ba becibo efectiva entrega de las enunciadas 80 libras." APrZ, Anastasio Marin, 1820, fols. 144v y ss.

39 APrZ, Manuel Gil Burillo, 1816, fol. 704. 
cia, esto fue lo más importante, lo que, desde nuestro punto de vista, otorga a las dificultades por las que atravesaron los regulares durante el primer tercio del Ochocientos una trascendencia que va más allá de los problemas puramente económicos o financieros.

La obligación estaba diseñada como una fórmula de expropiación mucho más rápida y eficaz que el censo consignativo, y su "ensayo" con las comunidades religiosas estaba demostrando que, al contrario que el sistema censal, esta nueva modalidad crediticia no distinguía entre los institucionalizados estados o estamentos. La obligación, como instrumento de crédito en manos de la clase ascendente, no privilegiaba a nadie. De la misma manera que la sociedad feudal, como defendimos en otro lugar ${ }^{40}$, había creado y desarrollado un mecanismo de crédito a la medida de sus intereses, de los de su clase dominante, la clase ascendente en el proceso de transición hacia el capitalismo delineó otro a la medida de los suyos, en donde ya no tenían cabida las situaciones de desigualdad jurídica ni los privilegios, como se demostró suficientemente.

Desde el momento en que las comunidades religiosas se vieron obligadas a traspasar propiedades a los prestamistas para satisfacer las deudas contraídas con anterioridad, o cuando debieron vender parte de sus haciendas ante la presión de los acreedores o, simplemente, cuando la enajenación del patrimonio no pudo ser evitada por los mecanismos tradicionales (censos)..., algo estaba cambiando al margen de la propia situación de crisis financiera de la economías conventuales. La propiedad feudal se enfrentaba al capital, pero, en estos momentos, éste le ganaba la batalla. La obligación resultaba incompatible con el sistema de amortización, no contemplaba que pudieran darse "casos" o situaciones que encorsetaran el desarrollo y reproducción del capital y, simplemente, no respetaba lo que hasta entonces había constituido una de las claves del dominio de la Iglesia en el sistema feudal: la amortización. En la medida en que esto era así, el régimen de amortización de la tierra había perdido - estaba perdiendo - todo su contenido frente a las exigencias del capital antes de que Mendizábal convirtiera en mercancía los patrimonios de la Iglesia.

40 Atienza (1987) 


\section{BIBLIOGRAFIA}

Artola, Miguel (1977): «Propiedad, asignación de recursos y distribución de rentas en la agricultura del Antiguo Régimen", Estudios de Historia Social, núm. 1 (abril-junio), pp. 11.53 .

AtienZA, Angela (1987): "El préstamo en la sociedad tardofeudal: las rentas censales del clero regular zaragozano en el siglo XVIII", Jerónimo Zurita, núm. 55, pP. 67-103.

- (1988): Propiedad, explotación y rentas. El clero regular zaragozano en el siglo XVIII, Zaragoza, Diputación General de Aragón.

BenNassar, Bartolomé (1983): Valladolid en el Siglo de Oro. Una ciudad de Castilla y su entorno agrario en el siglo XVI, Valladolid, Ayuntamiento.

Clavero, Bartolomé (1977): "Prohibición de la usura y constitución de rentas", Moneda y Crédito, núm. 143, pp. 107-131.

- (1985): Usura. Del uso económico de la religión en la bistoria, Madrid, Tcenos.

Fernández de PINedo, Emiliano (1985): "Del censo a la obligación: modificaciones en el crédito rural antes de la primera guerra carlista en el País Vascon, en García Sanz, Angel, y Garrabou, Ramón (eds.): Historia agraria de la España contemporánea. 1. Cambio social y nuevas formas de propiedad (1800-1850), Barcelona, Crítica, pp. 297-305.

FONTANA, José (1974): La quiebra de la monarquía absoluta, 1814-1820, Barcelona, Ariel.

García SANZ, Angel (1977): Desarrollo y crisis del Antiguo Régimen en Castilla la Vieja. Economia y sociedad en tierras de Segovia de 1500 a 1814, Madrid, Akal.

Gómez Alvarez, J. Ubaldo (1977): "El censo redimible y al quitar: un mecanismo teal de transferencia de la propiedad", Estudis, núm. 6, pp. 5-25.

GonzÁlez de MOlina, Manuel (1985): Desamortización, deuda pública y crecimiento económico. Andalucia, 1820-1823, Granada, Diputación, pp. 221-258.

Lemeunier, Guy, y Pérez PiCAzo, M.. Teresa (1984): El proceso de modemización en la región murciana. Siglos XVI-XIX, Murcia, Editora Regional.

LÓPEZ GARCíA, José Miguel (1987): "El ocaso de los institutos de regulares castellanos en las postrimerias del Antiguo Régimen", Hacienda Pública Española, núms. 108-109, Homenaje a Don Ramón Carande, pp. 311-325.

- (1990): La transición del feudalismo al capitalismo en un señorio monástico castellano. El Abadengo de la Santa Espina (1147-1835), Valladolid, Junta de Castilla y León.

Llopis AGELÁN, Enrique (1980): Las economias monásticas a fines del Antiguo Régimen en Extremadura, tesis doctoral, Universidad Complutense, Madrid, Servicio de Reprografía.

Marcos Martín, Alberto (1985): Economia, sociedad y pobreza en Castilla: Palencia, 1500-1814. Palencia, Diputación Provincial.

Millán, Jesús (1984): Rentistas y campesinos. Desarrollo agrario y tradicionalismo político en el sur del País Valenciano, 1680-1840, Alicante, Institución Juan Gil Albert.

PÉreZ SARrIón, Guillermo (1984): Agua, agricultura y sociedad en el siglo XVII. El Canal Imperial de Aragón, 1766-1808, Zaragoza, Institución Fernando el Católico.

Ruiz MAr'tín, Felipe (1970): "La banca en España hasta 1782", en El Banco de España. Una bistoria económica, Madrid, pp. 1-196.

- (1975): "Crédito y banca, comcrcio y transportes en la ctapa del capitalismo mercantil", en Actas de las I Jornadas de Metodologia Aplicada de las Ciencias Históricas, Universidad de Santiago de Compostela.

VIÑAS Y MEY, Carmelo (1941): El problema de la tierra en los siglos XVl y XVII, Madrid, CSIC.

VILLARES, Ramón (1982): "A economía do clero regular galcgo perante a desamortización", en Foros, frades e fidalgos, Vigo, Edicións Xerais de Galicia, pp. 15-76.

YUN CAsalilla, Bartolomé (1987): Sobre la transición al capitalismo en Castilla. Economia y Sociedad en Tierra de Campos, 1500-1830, Salamanca, Junta de Castilla y León. 